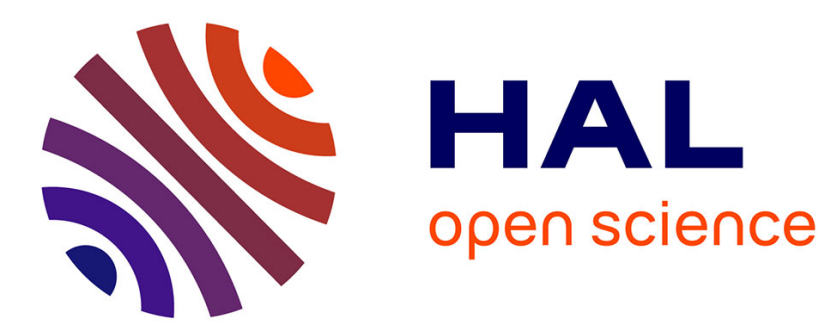

\title{
Band Structure Calculation of MnxCoyFe3-x-yO4
}

A. Rosenson, Ph. Tailhades

\section{To cite this version:}

A. Rosenson, Ph. Tailhades. Band Structure Calculation of MnxCoyFe3-x-yO4. Journal de Physique IV Proceedings, 1997, 07 (C1), pp.C1-181-C1-182. 10.1051/jp4:1997166 . jpa-00255113

\section{HAL Id: jpa-00255113 https://hal.science/jpa-00255113}

Submitted on 1 Jan 1997

HAL is a multi-disciplinary open access archive for the deposit and dissemination of scientific research documents, whether they are published or not. The documents may come from teaching and research institutions in France or abroad, or from public or private research centers.
L'archive ouverte pluridisciplinaire HAL, est destinée au dépôt et à la diffusion de documents scientifiques de niveau recherche, publiés ou non, émanant des établissements d'enseignement et de recherche français ou étrangers, des laboratoires publics ou privés. 


\title{
Band Structure Calculation of $\mathrm{Mn}_{x} \mathrm{Co}_{y} \mathrm{Fe}_{3-x-y} \mathrm{O}_{4}$
}

A. Rosenson and $\mathrm{Ph}$. Tailhades*

Dept. Appl. Math., Kuban State University, 12 Vystavochnaya St., apt. 7, Krasnodar 350072, Russia

* LCMI, URA 1311 du CNRS, Université Paul Sabatier, 118 route de Narbonne, 31062 Toulouse cedex,

France

\begin{abstract}
Electreric band structure of $\mathrm{Mn}_{k} \mathrm{Ca}_{3} \mathrm{Fe}_{3-3-y} \mathrm{O}_{4}$ has been calculated in high symmetrical points and lines of the first Brillouin zone within the scope one-electron quasirelativistic pseudopotential appreach. Atomic potential form-facters have been calculated in accordance with modified LCAO method. Dependence of energy gap $\mathrm{E}_{\mathrm{B}}=\mathrm{E}_{\mathrm{g}}(\mathrm{z}, \mathrm{y})$ against $\mathrm{Mn}$, Co and $\mathrm{F}_{e}$ concentrations is calculated and presented.
\end{abstract}

We assumed that the solid solution $\mathrm{Mn}_{\mathrm{x}} \mathrm{Co}_{5} \mathrm{Fe}_{3-x-\mathrm{y}} \mathrm{O}_{4}(\mathrm{MCFO})$ [1] is crystallized in structures with $\Gamma_{\mathrm{f}}^{f}$ Bravais lattice and space graup symmetry $O_{h}{ }^{7}$. Eight formulas units form the elementary cell. The main vectors of reciprocal lattice and high symmetrical paints and ines ceerdinates have been extracted from [2]. Lattiee parameters a=a( $x, y)$ hare been measured experimentally (Table 1). The basic vectors $(\vec{\tau})$ for coordinates of nonequivalent ions in elementary cell have been obtained from [3].

Tablel. Lattice ennstants for MCFO spinels

\begin{tabular}{|lrc|}
\hline$x$ & $y$ & Lattice constant (nm) \\
0.44 & 0.18 & 0.8449 \\
0.00 & 1.00 & 0.8395 \\
0.12 & 1.00 & 0.8408 \\
0.45 & 0.98 & 0.8419 \\
0.94 & 1.05 & 0.8435 \\
0.40 & 0.93 & 0.8415 \\
\hline
\end{tabular}
It is well-known that spin-orbit interaction influences on the band structure and optical characteristics such material as $\mathrm{Ni}(\mathrm{Z}(\mathrm{Ni})=28$, further $Z$ - is the total nuclear charge for one MCFO chemical formula) [4]. So the spin-orbit interaction term has been taken into account and electronic band structure of MCFO has been calculated within the scope one- electron pseudopotential approach by means of quasirelativistic Schroedinger equation solving [5]

$$
\left.\left\{-\frac{\hbar^{2}}{2 m} \nabla^{2}+V(\vec{\eta})+\frac{\hbar}{4 m^{2} c^{2}} \vec{\sigma} \nabla V, \vec{p}\right]\right\}=E \Psi
$$

which is equivalent to the system of equations:

$$
\begin{aligned}
& (T+V) \Psi_{1}+\frac{\hbar}{4 m^{2} c^{2}}\left[l_{3} \Psi_{1}+\left(l_{1}-i_{2}\right) \Psi_{2}^{\prime}\right]=E_{1} \Psi_{1}, \\
& (T+V) \Psi_{2}+\frac{\hbar}{4 m^{2} c^{2}}\left[\left(l_{1}+i l_{2}\right) \Psi_{1}-l_{3} \Psi_{2}\right]=E_{2} \Psi_{2}
\end{aligned}
$$

where $T=-\frac{\hbar^{2}}{2 m} \nabla^{2}, \quad \Psi_{r}(\tau$-is the spin index, $\tau=1$ for spin in "up"-state, $\tau=2$ for spin in "down"-state $)$ - is a spinor component for valent electron, $l_{i}=\varepsilon_{y k} \frac{\partial V}{\partial x_{y}} p_{k}, p_{k}=-i \hbar \frac{\partial}{\partial x_{k}} . \vec{r}=\left(x_{1}, x_{2}, x_{3}\right)$.

$$
\begin{aligned}
& \Psi_{\tau}=\Psi_{b r \mu m}^{j}(\vec{r})=\sum_{m=1}^{N} a_{m}^{j} S P W_{b s \mathrm{~s} m m}^{j}(\vec{r}), \\
& S P W_{b r g r m}^{j}(\vec{r})=\sum_{i=1}^{h} C_{\mu r}^{j}(l, m) \chi_{b_{r}} \exp \left\{i \alpha_{l}\left(\vec{k}+\overrightarrow{B_{m}}\right) \vec{r}\right\} \\
& C_{\mu y}^{j}(l, m)=D_{y, l}^{I^{*}}(l) \exp \left[-i \alpha_{l}\left(\vec{k}+\overrightarrow{B_{m}}\right) \overrightarrow{V_{l}}\right],
\end{aligned}
$$

$\chi_{b x}-\tau$-component of the valent electron spin function. $D_{v \mu}^{i}(l)-(v, \mu)$-th matrix element of the j-th irreducible representation for $\alpha_{1}$ - l-th element of the point subgroup $G_{0 \vec{k}}$ of the wavenumber group $G_{\vec{k}} \rightarrow m$-counter of the reciprocal lattice vector $\overrightarrow{B_{m}}, \mathrm{~h}$ - mumber of the elements in $G_{a k} \overrightarrow{V_{l}}$-nontritial translation for $\alpha_{l}$. The electron potential energy $V(r)$ is a superposition of the such energies in a vicinity of s-th atom in p-th primitive cell $\left(\vec{R}_{p}-\right.$ is a lattice vector $)$ : 


$$
V(\vec{r})=\sum_{n=s} v^{s}\left(\vec{r}-\vec{R}_{p}-\overrightarrow{\tau_{s}}\right)
$$

Iet us transform $(1,2)$ to a generalized eigenvalue problem $H X=E S X$, where $X$-the vector-function, $H, S-H e r m i t i a n$ N+N matrices with matrix elements:

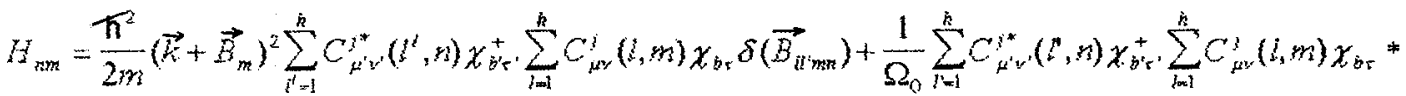

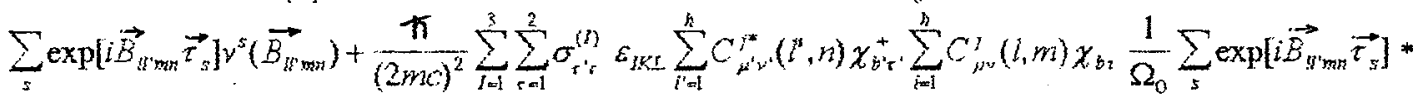

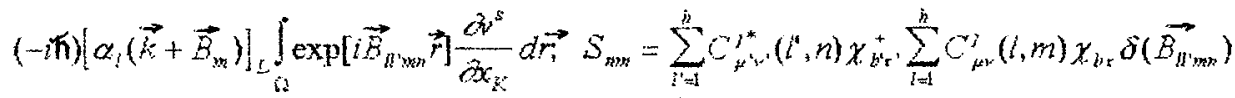

where $\vec{B}_{l i m m}=\alpha_{i}\left(\vec{k}+\vec{B}_{m}\right)-\alpha_{i}\left(\vec{k}+\vec{B}_{n}\right), \delta\left(\vec{B}_{i l m}\right) \cdots$ Kroneker's symbol, $\Omega_{0}$, the primitive ceil volume, $\Omega-$ the crystal volurise, $O(I)$ - the l-th Pauli matrix. $v^{5}\left(\vec{B}_{z^{\prime} m n}\right)$ is the Fourier component of atomic potential $\psi^{5}$ which has been extracted from $[0]$. $L$ is the Cartesian coordinate. For cation sublattice of MCFo $v^{3}=\left(L_{(M)} x+(C O) y+(F e)(3-x-y)\right) / 3$. For $\mathrm{K}=1, \mathrm{~L}=2$ integral in (4) has the form:

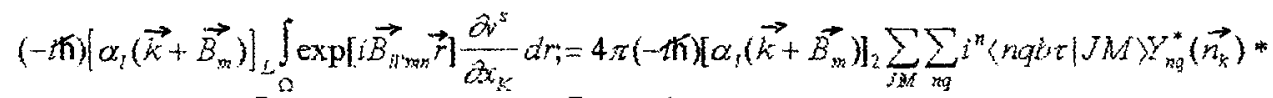

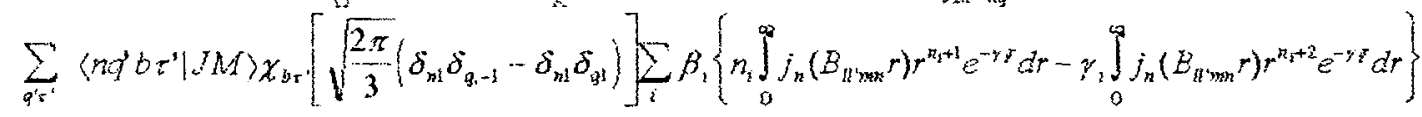

$$
\begin{aligned}
& \text { where } \int_{0}^{n}(k r) r^{m+1} e^{-*} d r=\frac{k^{n+1 / 2} \Gamma(m+n+2)}{2^{n+1 / 2}\left(y^{2}+k^{2}\right)^{(n+m+2) / 2} \Gamma(n+3 / 2)} F\left(\frac{n+m+2}{2}, \frac{n-m}{2}, n+3 / 2, \frac{k^{2}}{y^{2}+k^{2}}\right)
\end{aligned}
$$

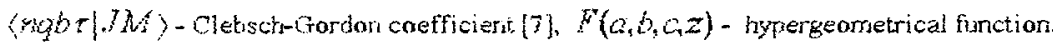

Bund structure calculations have been carried out in points $\Gamma, X^{\prime}$ and along lines $\Delta^{\prime}, \Sigma$ for $x, y$ from Table 3 . The results of band gap $\left(E_{g}\right)$ calculation for MCFO is presented in Figl. If $Z$ - is the total nuclear charge for orie MCFo chemical formula then we can to take into account that $\left(E_{g}\right)$ is increased when $Z$ is decreased. The results of band structure calculation are presented and discussed.

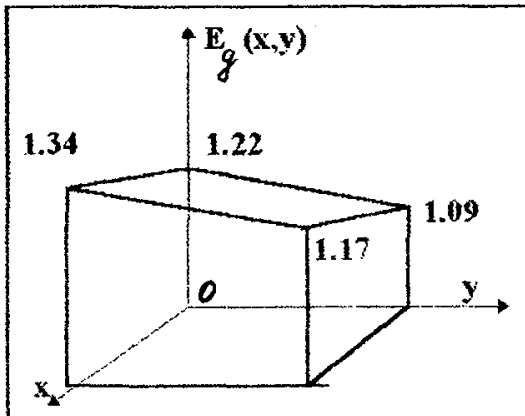

Fid. 1. Band gap of MCFO animet:

\section{References}

11) Ph.Tailhades at al. "New Mo and Co-Mo substituted ferrites: spinels with wery high coercitjuity". Proc of ICFG Tokyo 1992, pp.991-994.

[2] O.Y.Kovalev. Irreducible and induced representations and coreprescrtatione of the Fedoro's groups. Moscow, Wauka $1386,368 \mathrm{pp}$.

[3] International Tables for Crystallography. V.A, Space Group Symmetry. Dordrecht-Boston: I Reidel Publishing Company 1983.

[4] L. Hodges, D.K. Stoune, AV.Gold Phys.Rev.Lett. 1967, v. 19, p.655.

[5] F.Bassani, G.Pastori-Paravicini Electronic States and Optical Trarsitions in Solids Pergamon press. $1975,140$.

[6] MD Koterlin at al. "New modification of LCAO method for crystals with d-elements". Solid State Phys. (Russian), 1994, $\$ 36$, No. 6, pp. 1610-1614.

[7] D.A Varshalovich, AN.Moskalez, V.K.Khersonsky Quantum Theory of Angular Momentum Leningrad, Nauka, 1975, 439 p. 